\title{
The effect of social information processing (SIP) model intervention on reducing challenging behavior among children with mild to borderline intellectual functioning
}

\section{Mourad Ali Eissa Saad ${ }^{1}$, Hala Ahmed Seliman Hassanein ${ }^{2}$}

${ }^{1}$ KIE University, Baltim

${ }^{2}$ Imam Mohammed Ibn Saud Islamic University, Riyadh

\section{Egypt}

Saudi Arabia

Correspondence: Mourad Ali Eissa Saad, Vice President of KIE University E-mail: profmouradali@gmail.com https://orcid.org/0000-0002-1520-4482 


\begin{abstract}
Introduction. It is believed that children with mild to borderline intellectual functioning are not successful in processing the information received from peers and other people in their surroundings during social interactions, which leads to challenging and aggressive behavior. The purpose of this study was to investigate the effect of social information processing (SIP) model intervention on reducing challenging behavior among children with mild to borderline intellectual functioning.
\end{abstract}

Method. For the purpose of this study, a two-way repeated measures ANOVA, with pre-post - and follow up test in two groups were employed. A total of 40 children in the age of 5-10 participated. Participants were 33 boys and 7 girls with a mean age of $8.32(\mathrm{SD}=3.14)$ and a mean IQ of $75.64(\mathrm{SD}=7.34)$.

Results. Findings from this study revealed the effectiveness of social information processing (SIP) model intervention on reducing challenging behavior among children with mild to borderline intellectual functioning.

Discussion and Conclusion. In conclusion, results from this study suggested that children with mild to borderline intellectual functioning utilized the Social Information Processing (SIP) Model and their challenging behaviors and prosocial behaviors (challenging behavior) could be reduced. Application and implications, limitations, future research were included.

Keywords: social information processing (SIP) model, challenging behavior, children with mild to borderline intellectual functioning 


\section{Resumen}

Introducción. Se cree que los niños con un funcionamiento intelectual leve a límite no tienen éxito en el procesamiento de la información recibida de sus compañeros y otras personas en su entorno durante las interacciones sociales, lo que conduce a un comportamiento desafiante y agresivo. El propósito de este estudio fue investigar el efecto de la intervención del modelo de procesamiento de información social (SIP) en la reducción del comportamiento desafiante entre los niños con un funcionamiento intelectual leve a límite.

Método. Para el propósito de este estudio, se empleó un ANOVA de medidas repetidas bidireccionales, con prueba previa y posterior en dos grupos. Participaron un total de 40 niños de 5 a 10 años. Los participantes fueron 33 niños y 7 niñas con una edad promedio de 8.32 (DE $=3.14)$ y un coeficiente intelectual promedio de $75.64(\mathrm{DE}=7.34)$.

Resultados. Los resultados de este estudio revelaron la efectividad de la intervención del modelo de procesamiento de información social (SIP) para reducir el comportamiento desafiante entre los niños con un funcionamiento intelectual leve a límite.

Discusión y conclusión. En conclusión, los resultados de este estudio sugirieron que los niños con un funcionamiento intelectual de leve a límite utilizaron el Modelo de Procesamiento de Información Social (SIP) y que sus comportamientos desafiantes y prosociales (comportamiento desafiante) podrían reducirse. Se incluyeron aplicación e implicaciones, limitaciones, investigaciones futuras.

Palabras clave: modelo de procesamiento de información social (SIP), comportamiento desafiante, niños con funcionamiento intelectual leve a límite 


\section{Introduction}

Intellectual disability (ID), an equivalent term for intellectual developmental disorders (Al Said, 2014; APA, 2013; Mourad \& Hisham, 2013) is a neurodevelopmental disorder that is likely to be characterized by significantly impaired intellectual and adaptive functioning. Moreover, adaptive functioning, not IQ score, is supposed to determine the level of supports required (APA, 2013).Children with intellectual disability are impaired in everyday adaptive functioning, compared to their same age, gender, and socioculturally matched peers (Ditta, 2016; Mourad, 2013; Mourad \& Adel, 2019).

Children with intellectual disability are characterized by the prevalence of problem behaviors such as self-injurious behavior, stereotyped behavior, and aggressive/destructive behaviors (Masahiko, 2019).Challenging Behavior has recently been commonly used in in research studies in relation to developmental disabilities such as Intellectual disability (Masahiko, 2019).Challenging behaviour is likely to refer to such behaviours as aggression, self-injury, and destruction. Those behaviors are dangerous and pose significant risks to the child's health and safety and to that of those around them. They are not a diagnosis but can be said a descriptor of behaviours that occur in certain contexts with many possible causes (Gyles et al., 2014).

Additionally, such behaviors often result from an interaction between personal and environmental factors, interfere to have something to do with limiting the intellectual disabled child 's ability to effectively participate in his/ her community, reduce chances of learning new skills, impede engagement in activities that are meaningful, lead to a poorer quality of life, can be a major barrier against social adaptation and may result in further problems such as abuse and long-term hospitalization. (Masahiko, 2019; ONTABA,2019). Children with mild to borderline intellectual functioning (MBID) can be characterized by the inadequate social skills (Schalock et al., 2010) which are supposed to be the main cause for behavior problems (van \&Vriens, 2012), antisocial and delinquent behavior (Douma, Dekker, DeRuiter, Tick, \& Koot, 2007).

In treating challenging behavior, there are increasingly evidence-based psychosocial interventions that adopt evidence- based interventions (Masahiko, 2019). Social information processing (SIP) is among these approaches. Dodge's (1986) model describes how people 
respond to social cues using social cognitions. This approach, reformulated by Crick and Dodge (1994) proposed that there are six steps, influence one another, by which children process social information (see Figure1). The SIP model by Crick and Dodge (1994) distinguishes several steps: encoding of cues, interpretation of cues, clarification of goals, response access, response decision, and behavioral enactment (Mourad, 2017). These six steps occur simultaneously within the context of different kinds of social situations (Hasanin,2015). The steps are not presumed to be dependent on one another (Jennifer et al.,2009).

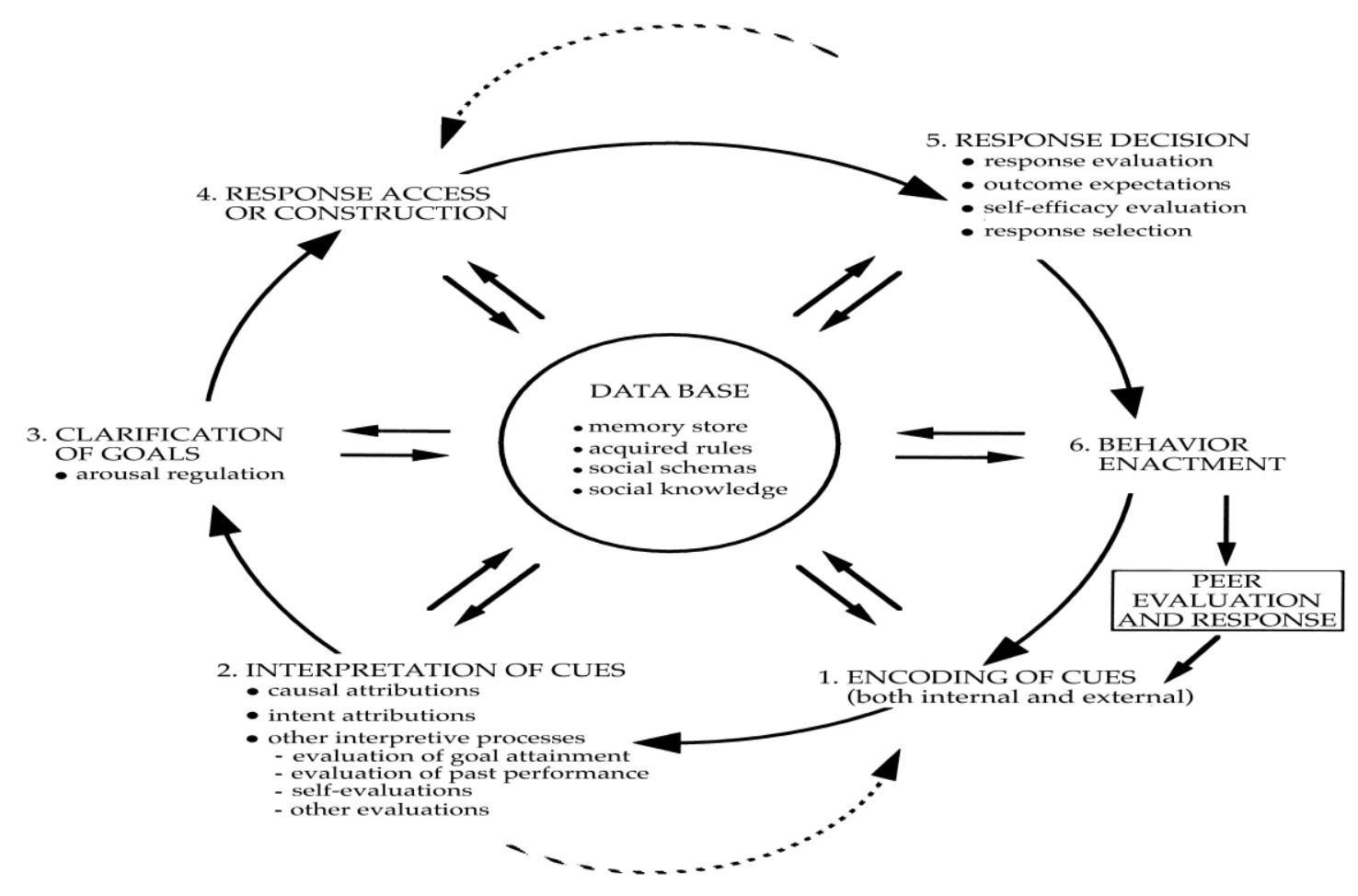

Figure 1. Crick and Dodge's (1994) Reformulated Social Information Processing Model

Crick and Dodge posed that the child is likely to enter a certain social situation with a combination of "biologically limited capabilities and a database of memories of past experiences" (Crick \& Dodge, 1994, p.76), and there are many factors that set limits on what children notice and process about a situation, among them are selective attention, perception, memory, and processing speed (Lemerise \& Arsenio, 2000).

Training in Social Information Processing Model (SIPM) led to peer acceptance and reduction of aggressive problem behaviors (Abu al-Fadl, 2014; Fraser, Day,Galinsky, Hodg- 
es, \& Smokowski, 2004a; Fraser et al., 2004b; Smokowski, Fraser, Day, Galinsky, \& Bacallao, 2004; Khalifa, 2014). Nevertheless ,little is known about using Social Information Processing Model (SIPM) with children with mild to borderline intellectual functioning.

The aim of the present study was to examine the effect of social information processing (SIP) model intervention on reducing challenging behavior among children with mild to borderline intellectual functioning.

\section{Problem Statement}

As indicated by DSM-5(2013), children with mild to borderline intellectual disabilities (MBID) are likely to have problems with adaptive functioning in social situations and in their relations with peer. They have problems building social relations as their peers are less likely to accept them or they even reject them. A such they have problems developing adequate social skills and their interactions with other especially their peers become problematic. The main reason for this peer less acceptance or rejection is their "Challenging Behavior" which acts as a major barrier against social adaptation.

This study poses the following hypotheses:

Hypothesis 1: There are significant differences in post- test scores mean between control and experimental groups on the Early Childhood Behavior Screen.

Hypothesis 2: The intervention is effective, and the effect is still evident in a follow up measurement after a month from the first intervention.

\section{Method}

\section{Participants}

In the present study a total of 40 children in the age of 5-10 participated. Participants were 33 boys and 7 girls with a mean age of $8.32(S D=3.14)$ and a mean $I Q$ of 75.64 $(S D=7.34)$. The children were selected from Trabya Fekyia Schools for children with Intellectual disability, in Desok and Baltim Edaras, in order to obtain two groups. The first researcher confirmed that any information children would provide would be top secret and confidential. It would not be revealed to anyone. It would be used for research purpose only. Each child participant met the criteria for mild to borderline intellectual functioning. Intellectual ability scores ranged from 50-84, consistent with a mild to borderline intellectual functioning 
(Schalock et al., 2010). Intellectual ability was based on Stanford -Binet intelligence Scales ( 5 ed.). The children in the first experimental group, the Baltim Edara, have mild to borderline intellectual disabilities. The children in the second control group, the Desok Edara, have mild to borderline intellectual disabilities. Criteria for these children to be included are that they are below-average intellectual functioning and limitations in social and adaptive behavior (APA, 2013). 9 children (22.5\%) came from families with low socioeconomic status of which 2 (22.22\%) with parents who had not finished any formal education, 3 (33.33\%) with parents who finished only elementary school, and 4 (44.449\%) with secondary school education. The remaining children came from families with medium socioeconomic status $21(52.5 \%)$ and high socioeconomic status 10(25.0\%). Table 1. shows demographic and diagnostic characteristics of children participants.

Table 1. Participant Demographics

\begin{tabular}{ll}
\hline & $\mathrm{N}=40$ children \\
\hline IQ & $75.64(\mathrm{SD}=7.34)$. \\
Age & $8.32(\mathrm{SD}=3.14)$ \\
Boys & $33(82.5 \%)$ \\
Girls & $7(17.5 \%)$ \\
socioeconomic status & Low to moderate to high \\
\hline
\end{tabular}

\section{Instruments}

The Early Childhood Behavior Screen (Holtz and Fox ,2012). This scale aims to ask teachers to evaluate their child's behaviors from the past week. The scale was created with parents rating how often they witnessed their children's behaviors. However, the researchers changed the scale to be rated by teachers instead of parents. It is a 20 questions with a 3-point Likert scale from 1 = almost never, 2 = sometimes and 3 - often. The scale was divided into two sub-scales, challenging behaviors and prosocial behaviors. Reliability of the Early Childhood Behavior Screen was.87 and .92 for challenging and prosocial behavior subscales, respectively (Holtz \& Fox, 2012). For the current study, the internal reliability of the scale was acceptable (Cronbach's alpha $=.89$, for challenging behaviors and .92 for prosocial behaviors respectively). For convergent validity of The Early Childhood Behavior Screen, correlation with Al Sawi 's Child's Challenging Behaviour Scale (CCBS) (2014) was significant $[r(40)$ $=0.64, \mathrm{p}<0.01]$. The content validity of the scale was examined by a group of 10 experts. They assessed the relevance of each question using a four-point Likert scale (where 1 repre- 
sents "irrelevant" and 4 represents "highly relevant"). They provided suggestions and comments. The 20 questions were judged to be quite or highly relevant. A content validity index was calculated at the item level $(I-C V I=.90)$.

\section{Procedures}

Prior to administering the scales, the researcher informed children's parents with the help of social work teacher. They were given the option of accepting or refusing to allow their children's participation in the study. Children were also informed about purpose of the study. The training program is a 10-lesson intervention, that is comprised of Crick and Dodge (1994) 's SIP skills. Each lesson trains in one skill. Each lesson has a scenario. During the first and second lessons, children are trained on "encoding" where they will be able to identify and describe his / her inner feelings and will be introduced to the social / external cues. Children will enjoy meeting the faces of the bears. At the beginning of the session, the researcher tells the children that they will meet with some bears.

Scenario: "What are you looking at? I think I'm talking to you. Uh. You can say that I am angry or crazy, or sad all the time. I don't know why I always feel this way. People do everything that makes me angry. You know what I mean well. They take my things from me, and they get angry at me, and make me crazy. There is no one in the class who likes to play with me. They can be scared of me". Children can use body language or their faces to show the feelings of each bear.

During the fourth and fifth sessions, interpretation of cues, he student will recognize many of our responses to social cues. Once the information from the social and internal systems are attended to and perceived, the child must interpret the meaning of those cues. Children are given scraps of paper containing a story labeled" My days in color". The researchers reads, using body language and children follow.

Once the individual has interpreted the social and personal cues in the event, clarification of goals takes place. The child will set many goals. The child will use goals when dealing with a social situation. These goals are influenced by a child's feelings, temperament and adult instruction. The child will learn positive behavior and self-regulation. The researcher tells children" well, goals can be internal ( when you maintain or regulate your emotion) or external( when for example you set social relational goals in such a way that you like getting an- 
The effect of social information processing (SIP) model intervention on reducing challenging behavior among children with mild to borderline intellectual functioning

other to play with you" " when you are in positive moods, you may choose goals that maintain your pleasant moods.

During the fourth stage, the child is searching for possible and appropriate behavioral responses to the way he/she encodes and interprets the social information and to what goal he/she is working toward. Child's past experiences play a role. The researcher tries to expose the child to novel situation where responses may be constructed to respond to these social cues. The child will be able to evaluate multiple choices, choose the right action and provide justification for the choices. The child will be able to identify confidence and name the skill of solving problems that he is adept and should be used in the problematic social situation. The child will be able to select and predict the response.

During the fifth stage, the child chooses a response to the social situation. This is done carefully as child's responses involve specific behavioral capabilities that concern his/her ability to carry out the decision. Here again past experiences play a role. The researcher reiterates that in order for the student to be confident in the act, he must believe in the importance of the act (it will help them to achieve their goals). The researcher provides some simple examples such as (modeling):

- I know I can get the teacher to hear me if I wake up in class. But I am not sure that shouting will make me some time on the computer. It will not be useful. The researcher asks children: what's the problem? What needs to be changed

What are some possible goals?

What is the best goal?

What steps might you take?

The researcher explains to the children that sometimes the action will not be beneficial because it will not help to change the situation. For example, just wanting to be invited by the teacher will not change the situation. At other times, actions may not work because they do not fit the situation. For example, if you can yell in the classroom, the teacher might hear you, but it won't bring you what you want, because yelling does not fit the classroom.

The sixth and final step of social information processing occurs when the response is enacted. We call it the culmination of the process. The child will be able to respond to choice, fiction, poetry, and drama using evaluative, interpretative, and critical processes with 
conclusions on personalities, events and topics. The child will be able to evaluate multiple options, choose the appropriate action and provide justification for the choices. The child will be able to evaluate the success achieved. The child employs verbal and motor skills that have been developed through rehearsal, feedback, and practice in order to act out the chosen response.

The researcher gives the children a copy of the worksheet: I am really good at ... and ask them to draw a picture of a particular emotion performed well. Children may return to problem solving in the method of making choices and choosing a step. This skill should be one of the skills they feel confident in and perform well. Each child asks for a particular emotion (self-questioning), thinks aloud with his classmates (thinking out loud), and children exercise self-assessment (enacting).

The experimental group received ten sessions, each of which lasted for 25-30 minutes. All data were entered in an SPSS file.

\section{Design}

For the purpose of this study, a two-way repeated measures ANOVA, with pre-post - and follow up test in two groups were employed.

\section{Data analysis}

To test the hypotheses of the study, a two-way repeated measures ANOVA analyses were conducted.

\section{Results}

To test the first hypothesis, the researchers used the two-way ANOVA analysis for the differences in post- test mean scores between experimental and control groups in the Early Childhood Behavior Screen. The abbreviated analysis of variance output is shown in Table 2. $\mathrm{T}$ - test results for the differences in post- test mean scores experimental and control groups in The Early Childhood Behavior Screen are shown in Table 3. The results of the two-way ANOVA Table1. reported that $F(1,37)=417.574, p<.0005$. Further more, Table 2. Show T-test results for the differences in post- test mean scores between experimental and control groups in Letter Naming Knowledge. As shown, $\mathrm{T}=11.39$ for challenging behaviors, 15.11 
The effect of social information processing (SIP) model intervention on reducing challenging behavior among children with mild to borderline intellectual functioning

for prosocial behaviors, and 20.37 for the total score, $p<0.01$.(See figure 1 for the differences in mean scores on Early Childhood Behavior).

Table 2. Dependent Variable: Early Childhood Behavior(post-test)

\begin{tabular}{|c|c|c|c|c|c|c|}
\hline Source & $\begin{array}{c}\text { Type III Sum } \\
\text { of Squares }\end{array}$ & $\mathrm{df}$ & Mean Square & $\mathrm{F}$ & Sig. & $\begin{array}{l}\text { Partial Eta } \\
\text { Squared }\end{array}$ \\
\hline Corrected Model & $2541.446^{\mathrm{a}}$ & 2 & 1270.723 & 215.520 & .000 & .921 \\
\hline Intercept & 217.171 & 1 & 217.171 & 36.833 & .000 & .499 \\
\hline pre & 13.346 & 1 & 13.346 & 2.263 & .141 & .058 \\
\hline group & 2462.041 & 1 & 2462.041 & 417.574 & .000 & .919 \\
\hline Error & 218.154 & 37 & 5.896 & & & \\
\hline Total & 58710.000 & 40 & & & & \\
\hline Corrected Total & 2759.600 & 39 & & & & \\
\hline
\end{tabular}

a. R Squared $=.921($ Adjusted $\mathrm{R}$ Squared $=.917)$

Table 3. T-test results for the differences in post- test mean scores between experimental and control groups in Early Childhood Behavior

\begin{tabular}{lllcccc}
\hline Variables & Group & $\mathrm{N}$ & Mean & Std. deviation & T & Sig. \\
\hline challenging & Exp. & 20 & 14.95 & 2.64 & 11.39 & .000 \\
behaviors & Cont. & 20 & 23.05 & 1.76 & & \\
prosocial & Exp. & 20 & 14.5 & 1.84 & 15.11 & .000 \\
behaviors & Cont. & 20 & 22.3 & 1.38 & & \\
total & Exp. & 20 & 29.45 & 2.83 & 20.37 & .000 \\
& Cont. & 20 & 45.35 & 2.03 & & \\
& & & & & & \\
\hline
\end{tabular}




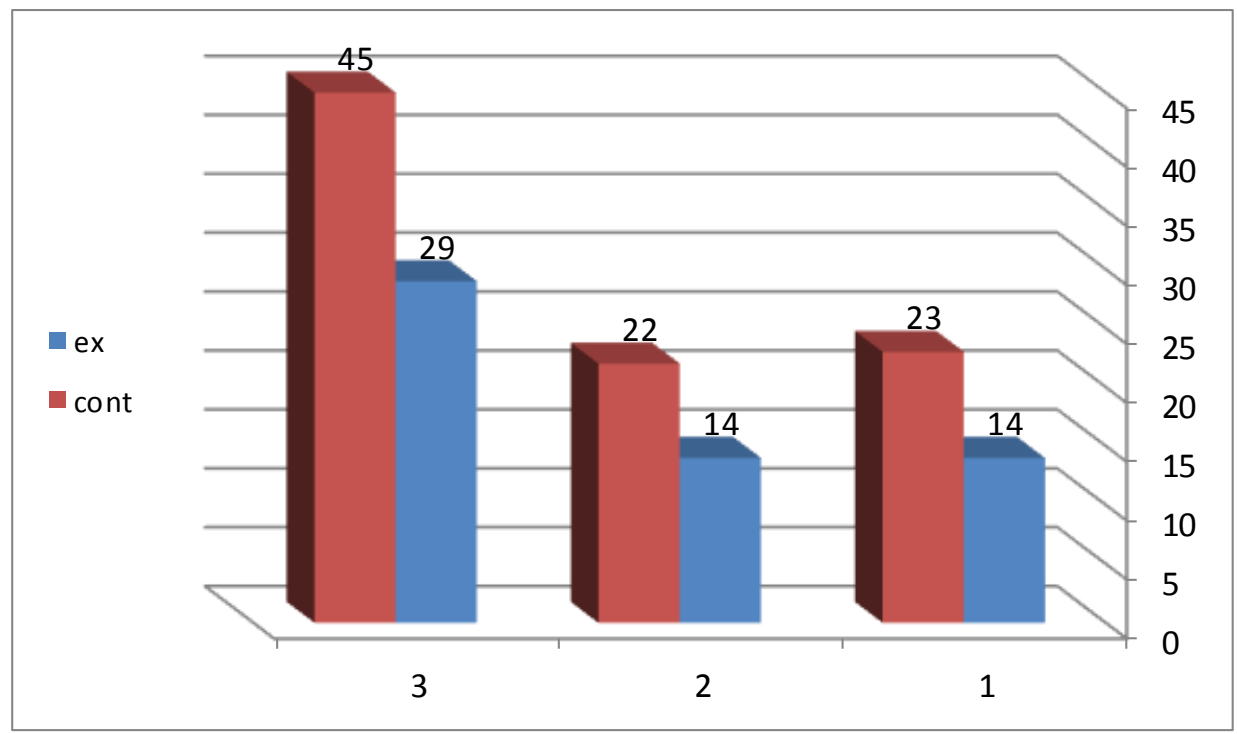

Figure 1. Experimental and control groups mean scores on challenging behaviors, prosocial behaviors, and total score

To test the second hypothesis, the researchers used repeated measures analysis. Table 4. shows data on repeated measures analysis for Early Childhood Behavior. The table shows that there are statistical differences between measures (pre- post- follow-up), $p<0.01$

Table 4. Repeated measures analysis for Early Childhood Behavior

\begin{tabular}{|c|c|c|c|c|c|}
\hline Source & $\begin{array}{l}\text { Type } 111 \\
\text { sum of squares }\end{array}$ & $d f$ & Mean square & $F$ & Sig. \\
\hline Between groups & 775.20 & 1 & 775.20 & 132.22 & 0.01 \\
\hline Error 1 & 222.78 & 38 & 5.86 & & \\
\hline Between Measures & 5104.04 & 2 & 2552.02 & 391.06 & 0.01 \\
\hline MeasuresxGroups & 1755.31 & 2 & 877.65 & 134.48 & 0.01 \\
\hline Error 2 & 495.96 & 76 & 6.52 & & \\
\hline
\end{tabular}


Table 5. shows data on Scheffe test for multi-comparisons in Early Childhood Behavior. The table shows that there are statistical differences between pre and post measures in favor of post test, and between pre and follow up measures in favor of follow up test, but no statistical differences between post and follow up measures.

Table 5. Scheffe test for multi-comparisons in Early Childhood Behavior

\begin{tabular}{llll}
\hline Measure & Pre & Post & Follow up \\
& $M=45.65$ & $M=29.45$ & $M=29.90$ \\
\hline Pre & -- & -- & -- \\
Post & $16.20^{*}$ & -- & -- \\
Follow up & $15.75^{*}$ & 0.449 & -- \\
\hline
\end{tabular}

\section{Discussion}

Children with mild to borderline intellectual functioning are affected by their early life experiences, though limited, as these shape their social knowledge or social repertoire. Early experiences that those type of children are exposed to may produce significant deficits in their social knowledge, hence, have impact on their subsequent behavior and relations with peers (Minna, Timo, Jukka, Heikki \& Vesa, 2014). When children with mild to borderline intellectual functioning enter school, they may be exposed to interventions that aim to change their maladaptive behaviors and beliefs (Thomas, Gautham \& Shekhar, 2019). For children with mild to borderline intellectual functioning, interventions such as Information Processing (SIP) Model may hold promise to change and reducing their challenging behavior in addition to their information-processing patterns.

Results from this study support the research hypotheses in general Compared to children in control group (comparison group), children in the experimental group (intervention condition) displayed decrease in challenging behavior. These findings are similar to earlier results (Abu al-Fadl, 2014; Khalifa, 2014; Maaike et al., 2018). 
The purpose of this study was to investigate the effect of social information processing (SIP) model intervention on reducing challenging behavior among children with mild to borderline intellectual functioning. In this respect, the findings extend our knowledge on the effect of social information processing (SIP) model intervention. Children with mild to borderline intellectual functioning are likely to be at high risk for developing challenging behavior and rule-breaking behavior problems and are predicted to be overrepresented in the juvenile justice system (Sainero, Del Valle, López, \& Bravo, 2013). Those children tend to encode negative social cues, interpret social cues with hostility, generate challenging and aggressive responses, and they prefer to select challenging and aggressive responses (Van Nieuwenhuijzen, Vriens, Scheepmaker, Smit, \& Porton, 2011).

It is believed that children with mild to borderline intellectual functioning are not successful in processing the information received from peers and other people in their surroundings during social interactions, which leads to challenging and aggressive behavior (Dodge and Crick, 1990). Nevertheless, the intervention based on social information processing (SIP) model aims to reduce challenging behavior of these targeted children, and thereby reduce their negative behaviors that are thought to be the result of cognitive deficits in social information processing (Wilson and Lipsey, 2006). the marked reduction in challenging behavior observed in the present study can be attributed to the beneficial effect of the intervention which is based on social information processing, and its six different stages.

As is clear in this study, social information processing (SIP) model in children with mild to borderline intellectual functioning presumes use of evidence-based practices, and is an emerging practice with a promise that will lead to greater levels of effectiveness in reducing the targeted children's challenging behavior

\section{Application and implications}

The finding of this study have practical implications for interventions and preventions of problem behaviors among children with mild to borderline intellectual functioning. Knowledge of the social information processing model is helpful for anyone seeking for reducing challenging behavior among children with mild to borderline intellectual functioning. Understanding of the order of the steps will help by allowing those who are interested and concerned to identify interventions that can happen early. Many of problem behaviors can be connected to biases and mistakes children with mild to borderline intellectual functioning 
have in making sense of social situations. Many of problem behaviors can be decreased by those who work with children with mild to borderline intellectual functioning who have an understanding of why these acts of behaviors occur in the first place and by knowledge and practice of effective interventions.

\section{Limitations}

Two main limitations emerged from this study. First, there were 40 children participants in this study which is a relatively small sample size, which may have made significant findings harder to detect In addition, children from which the sample was drawn was rural; therefore, generalization to children from other demographic backgrounds is difficult. Second, the length of the intervention was short. It should not have been less than 10 weeks long, as indicated by Sheridan, Kratochwill \& Bergan (1996). Despite these limitations, but it was noticed that children with mild to borderline intellectual functioning were responsive to the intervention and their challenging behaviors and prosocial behaviors ( challenging behavior) could be reduced.

\section{Future research}

This study relied on social information processing (SIP) model, aiming at reducing challenging behavior among children with mild to borderline intellectual functioning. The value of this study lies in the type of children from which data were gathered. Future research needs to include other types of children, e.g. children with ASD. We also suggest that future research studies replicate the findings of this study on a larger scale.

\section{Summary and conclusions}

The Social Information Processing (SIP) Model (Crick \& Dodge, 1994) can be regarded a detailed framework that helps in understanding the way that children, especially those with mild to borderline intellectual functioning make sense of and acts in different social situations. It is likely to offer some possible points for intervention and hence it is optimistic about the possibility of achieving change in children's behavior. In conclusion, results from this study suggested that children with mild to borderline intellectual functioning utilized the Social Information Processing (SIP) Model and their challenging behaviors and prosocial behaviors (challenging behavior) could be reduced. 


\section{Acknowledgements}

We'd like thank children who participated for their willingness to support.

\section{References}

Abu, M. (2014). Effectiveness Of Social Information Processing Skills Training Using Making Choices Program On Promoting Social Competence of Primary School Children With Aggressive Behavior. International Journal of Psycho Educational Sciences, 3(1), 8-16.

Al Said, A. (2014). The Effectiveness of a Phonological Awareness Training Intervention on Phonological Working Memory of Children with Intellectual Disabilities, International Journal of Psycho Educational Sciences, 3(1), 50-55.

Al Sawi, R. (2014). Using Social Stories To Improve Challenging Behaviors In Young Children With Emotional and Behavioral Disabilities. International Journal of Psycho Educational Sciences, $3(2), 91-99$.

Al shakhs, A. (2006). Family Socioeconomic Status. Cairo, Egyptian Anglo.

American Psychiatric Association (2013). Diagnostic and Statistical manual of mental disorders. Washington DC: APA, 51.

Crick, N. R., \& Dodge, K. A. (1994). A review and reformulation of social information processing mechanisms in children's social adjustment. Psychological Bulletin, 115, 74-101.

Ditta, B. (2016). Social Skills of Individuals with Intellectual Disabilities. International Journal of Psycho Educational Sciences 5(2). 68-77.

Dodge, K. A. (1986). A social information processing model of social competence in children. Minnesota Symposium in Child Psychology, 18, 77-125.

Dodge, K. A., \& Crick, N. R. (1990). Social information-processing bases of aggressive behavior in children. Personality and Social Psychology Bulletin, 16(1), 8-22.

Douma, J.C.H., Dekker, M.C., deRuiter, K.P., Tick, N.T., \& Koot, H.M. (2007). Antisocial and delinquent behaviors in youths with mild or borderline disabilities. American Journal on Mental Retardation,112, 207-220.

Fraser, M., Day, S., Galinsky, M., Hodges, V. G., \& Smokowski, P. (2004 a). Conduct problems and peer rejection in childhood: A randomized trial of the Making Choices and Strong Families programs. Research on Social Work Practice, 14, 313- 324.

Fraser, M., Rose, R., Terzian, M. A., \& Guo, S. (2004 b, October). Propensity Score Matching using STATA/PSMATCH2. Paper presented to the Applied Statistics Working Group at the University of North Carolina at Chapel Hill, Chapel Hill, NC. 
The effect of social information processing (SIP) model intervention on reducing challenging behavior among children with mild to borderline intellectual functioning

Gyles G., Sarah B., David B., Anthony H. and Andre S. (2014). Use of medication for challenging behaviour in people with intellectual disability. The British Journal of Psychiatry, 205, 6-7. doi: 10.1192/bjp.bp.113.141267

Hamoura, M. (2006). Stanford-Binet intelligence Scales (5 ed.). Cairo, Egyptian Anglo.

Hasanin, H. (2015). The effect of social information processing model training on improving social behaviour of with intellectual disabilities. International Journal of Psycho Educational Sciences, 4(1), 10-15.

Holtz, C.\& Fox, R. (2012). Early Childhood Behavior Screen [Database record]. Retrieved from PsycTESTS. doi: 10.1037/t24708-000.

Jennifer E., Patrick S., Kenneth A., Joseph C., Gregory S.\& John E. (2009). A 12-Year Prospective Study of Patterns of Social Information Processing Problems and Externalizing Behaviors. $J$ Abnorm Child Psychol, 34(5), 715-724.

Khalifa, W.(2014)The effectiveness of a training program based on Dodge's Social Information Processing Model on social competence of children with ADHD. International Journal of Psycho-Educational Sciences ,3(2), 141-153.

Lemerise , E. \& Arsenio, W.(2000). An Integrated Model of Emotion Processes and Cognition in Social Information Processing. Child Development, 71(1), 107-118.

Maaike M. Van Rest, Walter Matthys, Maroesjka Van Nieuwenhuijzen, Marleen H.M. De Moor, Aart Vriens \& Carlo Schuengel (2018): Social information processing skills link executive functions to aggression in adolescents with mild to borderline intellectual disability, Child Neuropsychology. https:/doi.org/10.1080/09297049.2018.1495186

Masahiko, I. (2019). Assessments and Interventions to Address Challenging Behavior in Individuals with Intellectual Disability and Autism Spectrum Disorder in Japan: A Consolidated Review. Yonago Acta Med. ,62(2), 169-181.

Minna P, Timo A, Jukka K, Heikki S, \&Vesa N. (2014). Borderline Intellectual Functioning: A Systematic Literature Review. Intellectual and Developmental Disabilities ,52 (6): 419-443.

Mourad, A. (2013). The Effectiveness of a Phonological Awareness Training Intervention on Prereading Skills of Children with Mental Retardation . International Journal of Psycho Educational Sciences, 2(2), 11-21.

Mourad, A.(2017).The effects of Cassady and Justin's Functional Model for Emotional Information Processing on improving social competence of first grade Children with ADHD. International Journal of Psycho Educational Sciences, 6(1), 86-94.

Mourad , A. \& Adel, A.( 2019).Defining and Determining Intellectual Disability (Intellectual Developmental Disorder): Insights from DSM-5 .International Journal of Psycho Educational Sciences, 8(1), 51-54. 
Mourad, A. \& Hisham, H. (2013). Effect of Multisensory Approach on Increasing Math Skills Children with Mild Intellectual Disabilities. International Journal of Psycho Educational Sciences, 2(3), 73-82.

ONTABA (2019). Report of the Ontario scientific expert task force for the treatment of challenging behaviour recommendations for caregivers, practitioners, and policy makers. Report of the Ontario scientific expert task force for the treatment of challenging behavior.

Sainero, A., Del Valle, J. F., López, M., \& Bravo, A. (2013). Exploring the specific needs of an understudied group: Children with intellectual disability in residential child care. Children and Youth Services Review, 35, 1393-1399.

Schalock, R. L., Borthwick-Duffy, S. A., Bradley, V. J., Buntinx, W. H. E., Coulter, D. L., Craig, E. M., Yeager, M. H. (2010). Intellectual disability: Definition, classification, and systems of supports. Eleventh edition. Washington, DC: American Association on Intellectual and Developmental Disabilities.

Sheridan, S. M., Kratochwill, T. R., \& Bergan, J. R. (1996). Conjoint behavioral consultation: A procedural manual. New York: Plenum Press.

Smokowski, P. R., Fraser, M. W., Day, S. H., Galinsky, M. J., \& Bacallao, M. L. (2004). School-based skills training to prevent aggressive behavior and peer rejection in childhood: Evaluating the Making Choices program. The Journal of Primary Prevention, 25, 233-251.

Thomas K, Gautham A. \& Shekhar P. (2019). Clinical Practice Guidelines for Assessment and Management of intellectual disability. Indian J Psychiatry. ,61(Suppl 2), 194-210.

Van N \&Vriens, A. (2012). Social Cognitive skills and social information processing in children with mild to borderline intellectual disabilities. Res Dev Disabil., 33(2), 426-434.

Van Nieuwenhuijzen, M., Vriens, A., Scheepmaker, M., Smit, M., \& Porton, E. (2011).The development of a diagnostic instrument to measure social information processing and its precursors in children with mild to borderline intelligence. Research in Developmental Disabilities, 32, $358-370$.

Wilson, S. \&Lipsey, M. (2006). The effects of school-based social information processing interventions on aggressive behavior, part II: Selected/Indicated Pull-out Programs. Campbell Systematic Reviews, doi:10.4073/csr.2006.6

Received: $27-12-2019$

Accepted: $12-05-2020$ 